\title{
Os verbos frasais (phrasal verbs) do inglês e suas traduções para o português: um enfoque sistêmico-funcional
}

\author{
The English phrasal verbs and their translations into \\ Portuguese: a systemic functional perspective
}

\author{
Marcelo Saparas ${ }^{*}$ \\ christian_matt@uol.com.br \\ Universidade Federal da Grande Dourados \\ Ulisses Tadeu Vaz de Oliveira ${ }^{* *}$ \\ ulisvaz@gmail.com \\ Universidade Federal de Mato Grosso do Sul
}

RESUMO: Este artigo trata da interface entre Estudos da Tradução e Linguística Sistêmico-Funcional (LSF) e, nele, abordamos os verbos frasais (phrasal verbs, $\mathrm{PVs}$ ) do inglês que, tradicionalmente, costumam desafiar tradutores e aprendizes da língua inglesa. Nosso enfoque foi (1) analisá-los sob a perspectiva da LSF e da pragmática e (2) verificar como suas traduções para o português podem interferir tanto na realização da concepção performativa da linguagem, quanto na compreensão de seu significado ideacional ou informativo. Trata-se de uma pesquisa quali-quantitativa com a participação dos acadêmicos de letras da Universidade Federal da grande Dourados-MS. As traduções dos alunos provaram que tanto o significado do verbo quanto o da partícula podem ser omitidos na expressão do processo.

PALAVRAS-CHAVE: Phrasal verb. Tradução. LSF. Metafunção Ideacional.

ABSTRACT: This article deals with the interface between Translation Studies and Systemic-Functional Linguistics (SFL). We approached the phrasal verbs (PVs) of English which traditionally tend to challenge translators and English language learners. Our focus was (1) to analyze them from the perspective of SFL and pragmatics and (2) to verify how their translations into Portuguese can interfere both in carrying out the performative conception of language and the understanding of its ideational or informative meaning. It is a qualitative and quantitative research with the participation of students from the Federal University of Grande Dourados-MS. The translations of the students proved that both the verb meaning and the particle can be omitted in the expression of the process.

KEYWORDS: Phrasal verb. Translation. SFL. Ideational metafunction.

\footnotetext{
Doutor em Linguística Aplicada e Estudos da Linguagem (LAEL) pela Pontifícia Universidade Católica de São Paulo; Professor da Universidade Federal da Grande Dourados

Doutor em Linguística Aplicada e Estudos da Linguagem (LAEL) pela Pontifícia Universidade Católica de São Paulo; Professor da Universidade Federal de Mato Grosso do Sul
} 


\section{Introdução}

Este artigo trata da interface entre Estudos da Tradução e Linguística Sistêmico-Funcional (doravante LSF) e, nele, abordamos os verbos frasais (phrasal verbs, doravante $P V s$ ) do inglês que, tradicionalmente, costumam desafiar tradutores e aprendizes da língua inglesa. O enfoque é (1) analisá-los sob a perspectiva da Linguística Sistêmico-Funcional e da pragmática e (2) verificar como suas traduções para o português podem interferir, tanto na realização da concepção performativa da linguagem, quanto na compreensão de seu significado Ideacional (c.f. LSF), ou informativo. Assim, este artigo tem como objetivo precípuo identificar, na análise das traduções para o português feitas pelos nossos alunos de graduação de Letras, casos em que as traduções dos PVs que retêm os significados individuais do verbo e partícula (cf. Leech; Svartvik, 2002) podem comprometer a realização performativa da linguagem e/ou alterar a construção dos significados ideacionais (cf. LSF), ou informativos, dos PVs originais.

Primeiramente quanto à definição de $\mathrm{PV}$, existe certa discordância entre estudiosos do tema. Em nossa análise, por estarmos interessados nos significados individuais do verbo e da partícula e não apenas à forma do PV, optamos por seguir as definições propostas por Celce-Murcia; Larsen-Freeman (1983) e Swan (1995). Celce-Murcia e Larsen-Freeman definem o PV como um verbo seguido de partícula, que pode ser uma preposição, um advérbio ou uma combinação dos dois. $O$ verbo e a partícula juntos funcionam como um único verbo, portanto um lexema. Em Swan, pode-se notar uma nítida preferência pelo termo two-word verb ao PV. O autor define PV como um verbo que se associa a uma partícula adverbial ou a uma preposição.

A estrutura dos PVs é uma peculiaridade da família das línguas germânicas (DAGUT; LAUFER, 1985; DARWIN; GRAY, 1999; FILLMORE; ATKIND, 1992) e, como um todo, na perspectiva pragmática, ocorre mais frequentemente na língua falada do que na escrita (CORNELL, 1985; DIXSON, 1982; SIDE, 1990). Alguns autores, como Stefan Thim (2012) declinam a ideia de que os PVs seriam "vícios da linguagem" e somente usados coloquialmente.

\section{Desafios e complexidades nas traduções dos PVs}


Para efeitos de comunicação, muitas vezes as nuances interpretativas dos PVs passam imperceptíveis para os interlocutores. Isso costuma ocorrer quando o PV traduzido não é sobejamente polissêmico ou possui um referente em português um tanto consolidado. Há, no entanto, certos elementos que concorrem para a dificuldade da tradução dos $\mathrm{PVs}$, como, por exemplo, a complexidade sintática envolvida. Apresentaremos a seguir alguns fatores e características importantes para as traduções.

Tipos de significados obtidos com o PV

Para Leech e Svartvik (2002), em termos de significados, os PVs podem:

(1) reter os significados individuais do verbo e partícula (e.g. sit-down);

(2) ser idiomáticos, ou seja, o significado da combinação não pode ser obtido dos significados individuais do verbo e partícula, como em catch on (entender), give in (render-se) e turn up (aparecer, chegar).

Ao tomar o português como língua alvo para a tradução no intuito de se buscar compreender os referidos PVs, tem-se que em (1), o falante reconhece dois elementos: sentar + movimento para baixo. No português, o movimento está condensado no verbo "sentar" ou é subentendido contextualmente. Em (2), há impossibilidade de associação com a língua alvo para tradução.

Verbos seguidos de sintagma preposicional

Muitos dos PVs possuem um objeto e, com a maioria deles, o advérbio pode vir antes ou depois deste objeto quando ele for um nome ou sintagma nominal (HILTUNEN, 1999). Entretanto, quando o objeto for um pronome pessoal, ele sempre aparece antes do advérbio. Em alguns casos, os PVs com objetos se assemelham a verbos seguidos de um sintagma preposicional. Exemplos:

(1) They ran over the cat. (atropelaram o gato)

(2) They ran over the bridge. (atravessaram a ponte correndo).

Leech e Svartvik distinguem, entre os PVs, uma combinação fixa de verbo + preposição, os verbos preposicionados (VPs) [p.ex., He applied for a new job] e argumentam que os VPs são comumente encontrados no final da oração, como em: 
$\mathbb{B}_{\text {disse }} \mathcal{A}$

ISSN: 1983 2435

That's the job he is applying for. No caso do português, não é possível realizar esse tipo de checagem.

Phrasal Prepositional Verbs (PPVs)

Atualmente nota-se o aumento de uma forma mais complexa de PV (NEVALAINEN, 1992, p. 423), a de três partes: verbo frasal-preposicional (Phrasal Prepositional Verbs). Leech e Svartvik (2002) chamam de verbos frasaispreposicionais os verbos, em registros mais informais, que podem formar expressões idiomáticas com um advérbio e uma preposição (p.ex., Samantha can put up with almost anything). Ao realizar a tradução para o português, no entanto, pode-se utilizar apenas um verbo (tradução sugerida: Samantha pode tolerar quase tudo). Porém, nesse caso, também no inglês é possível se utilizar um único verbo para substituir a estrutura composta. Neste caso, poder-se-ia substituir Samantha can put up with almost anything por Samantha can tolerate almost anything. Pela substituição é possível eliminar tanto a partícula up quanto a preposition with. Contudo, sabe-se que o registro tolerate sugere mais formalidade do que o PV put up with.

Além disso, embora essas formas possam ser usadas na voz passiva, não é comum a inserção de um advérbio entre a preposição e um objeto (p.ex., He can’t put up with definitely her)

Tipologia da língua: língua do tipo enquadre satélite

Talmy (1991), em seu trabalho sobre padrões de lexicalização em diferentes idiomas, observa que algumas línguas lexicalizam informações diferentes em relação ao verbo de movimento. Línguas como o inglês expressam movimento e o modo como esse movimento é feito; em línguas como o espanhol, por exemplo, o verbo normalmente converge as informações relativas a movimento acompanhadas por um trajeto ou direção de movimento (TALMY, 1991). O português segue a mesma estrutura do espanhol nesse caso. Como exemplo, podemos mencionar os verbos de movimento em espanhol entrar e salir (entrar e sair), expressando (movimento + direção), e os verbos ingleses de movimento, expressando noções semelhantes: move in / go in; neles, a noção de direção é indicada por uma partícula 
ou satélite externos ao verbo. Talmy (1991, p. 486) descreve, para o inglês e o espanhol, dois padrões tipológicos de expressão de movimento, propondo que a informação semântica sobre o movimento pode ser expressa em estruturas do tipo marcadores léxico-semânticos. A partir desta perspectiva, o idioma inglês teria um tipo de estrutura do tipo enquadre verbal (verb-framed), ou seja, uma língua na qual o verbo concentra todas as informações lexicais relevantes sobre o padrão de movimento. O espanhol, por outro lado, é uma língua do tipo enquadre satélite (satelitte-framed), ou seja, uma língua que expressa a informação lexical relevante ao movimento em estruturas do tipo satélite e não central.

O satélite de um verbo é uma categoria gramatical que inclui qualquer outro constituinte sem que seja um complemento nominal. O satélite pode ser um afixo ou um morfema livre e poderia ser equivalente às seguintes formas que existem em diferentes idiomas: partículas verbais do inglês, prefixos separáveis e inseparáveis alemães, prefixos russos, complementos verbais chineses, etc. Observemos essa diferença tipológica nos exemplos dados por Talmy na oração em inglês e sua tradução para o espanhol.

(1) The bottle floated out (a garrafa saiu flutuando)

(2) La botella salió flotando (a garrafa saiu flutuando).

Em (1), o verbo flutuar expressa noções de movimento + modo, isto é, movimento de modo que o corpo está suspenso acima de uma superfície (de líquido), e a partícula out codifica informações sobre a direção do movimento e pode ser considerada uma informação de satélite, ou seja, não-central. No exemplo (2), o verbo principal expressa movimento + direção (sair), enquanto as informações sobre a forma de como o corpo se move é expressa por um gerúndio, que age como um satélite (flutuando), ou seja, não-central. Assim, o modo de circulação em espanhol pode ser omitido ou movido para uma posição secundária ou de fundo.

O elemento chamado de satélite por Talmy (1991) é denominado circunstância na LSF, teoria que adotamos como base para nossa análise e que será expandida na próxima seção. Michael Halliday (1985, 1994), ao estabelecer as bases da Linguística Sistêmico-Funcional (LSF), mostrou como significados construídos nos enunciados linguísticos são descritos no uso sistemático da língua. A LSF vem sendo ampliada por colaboradores e é tida como a mais adequada (cf. FOWLER, 1991; FAIRCLOUGH, 1992; CHARTERIS-BLACK, 2004) para estudar a 
$\mathbb{B}_{\text {dişei }} \mathcal{A}$

ISSN: 1983 2435

conexão entre a estrutura linguística e os valores sociais refletidos no discurso e determinados pelas dimensões de contexto.

\section{A LSF e a transitividade}

A LSF é tida como uma teoria social porque se origina da sociedade e da situação de uso para o estudo da linguagem. Ela procura entender como se dá a comunicação entre os falantes, e estes se relacionam com a sociedade. É uma teoria tanto semiótica, pois se preocupa com a linguagem em todas as suas manifestações, quanto semântica, pois foca o texto como meio de comunicação humana e não apenas a oração. Assim, texto e unidade semântica têm papéis fundamentais nessa teoria.

Segundo a LSF, ao utilizarmos a língua, estamos construindo, simultaneamente, três significados, ou metafunções: Ideacional (informação), Interpessoal (interação) e Textual (construção linguística da informação e da interação) (HALLIDAY, 1994; HALLIDAY; MATTHIESSEN, 2004). Essa fusão é possível porque a língua possui um nível intermediário de codificação - a léxicogramática - que possibilita à língua essa concomitância de significados, que entram no texto por meio das orações.

A metafunção Ideacional representa os eventos das orações em termos de fazer, sentir ou ser. A metafunção Interpessoal envolve as relações sociais com respeito à função da oração no diálogo e referem-se a dar ou pedir informação ou bens e serviços. Finalmente, a metafunção Textual organiza os significados ideacional e interpessoal de uma oração, retrabalhando os significados que são representados em primeiro lugar ou no final da oração. Considerando nossa preocupação com o valor informacional alterado nas traduções de alguns PVs, aplicaremos essencialmente a metafunção Ideacional nesse artigo.

\section{Metafunção Ideacional}

De acordo com Thompson (2014), a categorização da oração em três tipos de constituintes (participantes, processo, circunstâncias) ajuda a associar as características funcionais dos constituintes às características estruturais da oração. Porém, apresentadas dessa forma, elas se mostram mais generalizadas em relação 
às características semânticas e gramaticais desempenhas por elas. Por consequência, cada uma delas é subdividida, considerando primeiramente a transitividade, que na LSF, é determinada pelo tipo de processo, descrito no Quadro 1, a seguir, ou pela ergatividade. Na subdivisão de processos, Halliday (1994) considera inicialmente dois tipos: os processos mentais (derivados da consciência ou da imaginação do indivíduo) e os materiais (derivados das experiências externas ao indivíduo). A esses processos, que provêm da nossa consciência de mundo e de nós mesmos, ele acrescenta um terceiro tipo que surge da nossa capacidade de generalizar ou classificar uma parcela da nossa experiência para outras pessoas; estes processos são chamados de processos relacionais. Apesar de Halliday (1994) considerar os três processos como os principais no sistema da transitividade da língua inglesa e de outras línguas, ele reconhece a existência de outros processos (comportamental, verbal e existencial) que se situam entre esses três; essa divisão dos processos é uma das formas com a qual Halliday indica a relação existente entre o sistema de transitividade e o modelo da nossa experiência.

Analisando o conteúdo e informação da oração, Halliday (1994, p. 107) detecta três componentes que não apenas servem de referência para a compreensão da nossa experiência como também correspondem às categorias semânticas da oração: (1) o processo; (2) os participantes do processo; e (3) as circunstâncias envolvidas no processo. Ele afirma que as categorias de processo, participante e circunstância geralmente evidenciam como o mundo é representado através de estruturas linguísticas, porém é necessário reconhecer que há funções específicas sendo desempenhadas por elas e que essas diferenças entre as funções estão relacionadas ao tipo de processo. Exemplificando, podemos apresentar o processo material, o qual descreve uma ação física de um dos participantes. Desse modo, quando a oração apresenta um processo material, haverá um participante chamado Ator, e outro chamado de Meta. Na oração ativa, quem faz a ação é denominado Ator. Caso a oração esteja na forma passiva, o Ator é descrito como agente e, embora algumas vezes este participante não apareça na oração, ele pode ser descoberto através da pergunta "por quem?". Já o participante para quem a ação se destina recebe o rótulo de Meta, porque o sentido depreendido deste termo envolve receber a ação feita por algo ou alguém. 
Quadro 1: Relação Processos/Participantes

\begin{tabular}{|c|c|c|c|}
\hline Processos & \multicolumn{2}{|r|}{ Participantes } & Circunstâncias \\
\hline Material & $\begin{array}{l}\frac{\text { João }}{\text { Ator }} \\
\frac{\text { Ele }}{\text { Ator }} \text { caminhou }\end{array}$ & $\begin{array}{ll}\frac{\text { sua chácara }}{\text { Meta }} & \text { ao vizinho } \\
\text { Beneficiário } \\
\text { pelo sertão. } \\
\text { Extensão }\end{array}$ & devido à seca. \\
\hline Comportamental & $\frac{\text { O sertanejo ger }}{\text { Comportante }}$ & $\begin{array}{l}\text { mia } \frac{\text { de agonia }}{\text { Comportamento }} \\
\text { Com }\end{array}$ & enquanto seguia. \\
\hline Mental & $\begin{array}{l}\text { Ele não r } \\
\text { Experienciador }\end{array}$ & mais acreditava em milagres. & \\
\hline Existencial & $\begin{array}{l}\text { A seca se fazi } \\
\text { Existente }\end{array}$ & ia presente. & no nordeste. \\
\hline Relacional & $\begin{array}{l}\text { (a) Atributivo: } \\
\text { (b) Identificativo: }\end{array}$ & 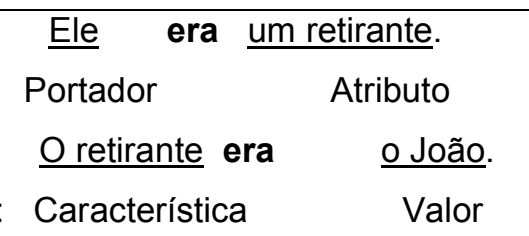 & \\
\hline Verbal & $\begin{array}{l}\text { O homem conto } \\
\frac{\text { seca. }}{\text { Dizente }}\end{array}$ & $\begin{array}{lll}\text { Du-nos } & \text { horrores } & \text { sobre a } \\
\text { Receptor Verbiagem } & \text { Alvo }\end{array}$ & \\
\hline
\end{tabular}

Fonte: Halliday (1994)

A seguir, outra teoria relevante para compor o arcabouço teórico desse estudo, o Princípio da Cooperação.

\section{O Princípio da Cooperação de Grice}

Ao iniciar seus estudos, a preocupação central de Grice era encontrar uma forma de descrever e explicar os efeitos de sentido que vão além do que é dito, em outras palavras, como é possível que um enunciado signifique mais do que literalmente é expresso. De acordo com Grice (1989), a comunicação é possível porque os interlocutores obedecem mutuamente o Princípio da Cooperação (PC). $O$ PC consiste de quatro máximas gerais: relevância, quantidade, qualidade e modo. Um falante que se conforma a essas máximas produz atos nítidos, claros e maximamente eficientes. Mas os falantes podem (e na verdade frequentemente isso acontece) desobedecer a essas máximas e, assim fazendo, expressam significados não literais. Se um ouvinte supõe que o falante esteja sendo cooperativo, então as violações do PC devem fazê-lo entender que o falante quer significar algo diferente 
daquilo que está dizendo literalmente. Como resultado, o ouvinte deve gerar uma implicatura conversacional (i.e. uma leitura não literal do que o falante diz).

Nesse sentido, Grice (1989) sistematiza quatro categorias fundamentais articuladas a máximas e submáximas:

1) Categoria da Quantidade

Relacionada à quantidade de informação que deve ser fornecida numa mensagem. A ela correspondem duas máximas: (a) faça com que sua mensagem seja tão informativa quanto necessária para a conversação. (b) não dê mais informações que o necessário.

2) Categoria da Qualidade

Relacionada inicialmente à supermáxima "procure afirmar coisas verdadeiras" e, indiretamente, a duas submáximas mais específicas: (a) não afirme o que você acredita ser falso. (b) não afirme algo para o qual você não possa fornecer evidência adequada.

3) Categoria de Relação

Ligada à máxima "seja relevante".

4) Categoria do Modo

Ligada à máxima "seja claro" e várias submáximas, entre outras: (a) evite obscuridade de expressão; (b) evite ambiguidade; (c) seja breve (evite prolixidade desnecessária); (d) seja ordenado.

Ao considerarmos os processos tradutórios em nosso estudo, pudemos notar que o Princípio da Cooperação de Grice (1975, apud SOUZA FILHO, 2006) foi estritamente observado no processo de tradução por nossos alunos, em especial a influência das máximas de quantidade e modo. Ou seja, ao traduzirem, eles procuraram manter o sentido das proposições, mas guiados pela orientação superior da Pragmática Conversacional. Portanto, houve uma evidente preocupação com a brevidade, clareza e a não ambiguidade.

\section{Metodologia}

Em estudo inicial sobre uso dos PVs, Santos e Nogueira (2004) observaram que seu índice de frequência é maior à medida que se aumenta a informalidade do texto. Sendo assim, a escolha do corpus de análise de nossa pesquisa observou os 
seguintes critérios: (1) textos informais, genuínos e curtos; (2) potencial dificuldade de tradução. Nesse contexto, optamos por oferecer aos alunos de graduação em Letras da Universidade Federal da Grande Dourados (UFGD) cinco textos originais extraídos do Twitter, e contendo PVs, para que fossem traduzidos.

Os PVs selecionados foram alguns que, por nossa experiência lecionando inglês, trariam alguma dificuldade aos alunos. Todos os PVs escolhidos foram do tipo que retêm os significados individuais de verbo e partícula (LEECH; SVARTVIK, 2002). A saber ${ }^{1}$ : fly back (Flew back to LA this morning. Watched and loved Big Eyes on the plane. Only 1 of 12 movie choices with female lead.); ride out (Rode out in Mount Laguna over the weekend with @[...] and @[...]); walk into (Walked into the office today\&was pleasantly surprised to find these little treasures hiding by the desk! \#UWS \#24Pct); write down (Why I Wrote Down Every Single Meal I Ate for a Year: [endereço de página da internet]); hand back (Daniel Andrews says Victoria wont hand back East West cash \#springst \#fedbudget).

Durante o processo de tradução, os 42 alunos, sendo 15 de primeiro semestre, 16 de terceiro semestre e 11 do quinto semestre, puderam utilizar dicionários e ferramentas de tradução online, e a única instrução que Ihes foi dada foi a de que apenas uma escolha poderia ser feita e que deveriam propor uma "boa" tradução dos PVs. A opção de escolher alunos de semestres diferentes foi de garantir estudantes com maior e menor experiência com o idioma. Também, a opção pela comanda de uma "boa tradução" foi notar quais escolhas léxico-gramaticais mais os agradaria, não somente como falantes nativos da língua, mas também, do mesmo modo, dentro do contexto da mensagem.

As traduções oferecidas por nossos alunos de graduação foram confrontadas com traduções padrões dos mesmos PVs obtidas por corpora online ${ }^{2}$. Interessa-nos, particularmente nessa pesquisa, a verificação de como as traduções online divergem das traduções feitas pelos alunos e o quanto o significado Ideacional pode ser discrepante em ambas as traduções. Para tanto, foram denominadas acepções

\footnotetext{
1 As fontes, acessadas em 02/06/15, foram: (fly back) https://twitter.com/LisaBloom/status/ 594931300101849088; (ride out) https://twitter.com/tony_turtle/status/554777319437373440; (walk into) https://twitter.com/LisaBloom/status/594931300101849088; (write down) https://twitter.com/ daninierenberg/status/ 594110294311325696; (hand back) https://twitter.com/rwillingham/status/ 598308206922715139.

${ }^{2}$ Por corpora online, entende-se os dicionários online e tradutores que, com sua tecnologia, podem ser úteis no processo tradutório de PVs devido à sua facilidade de acesso e à grande quantidade e variedade de dados online. Grosso modo, pode-se dizer que ferramentas como Google Translator e dicionários eletrônicos têm seu funcionamento atrelado aos princípios da linguística de corpus.
} 
padrão, neste caso, definições encontradas no dicionário Merriam-Webster e Dictionary and Thesaurus online, comparadas com as traduções da ferramenta Google Translate. Como exemplo, tem-se a definição do PV hand back, cuja tradução no Google Translate é entregar de volta, enquanto as definições nos referidos dicionários são to give, pass, or transmit with the hand .

Para contribuirmos nos estudos de tradução relacionados aos PVs do inglês para o português, buscamos examinar o perfil semântico dos itens lexicais em ambos os textos do original inglês e do português (traduzido), identificando os padrões emergentes na textualização e retextualização, além dos novos significados construídos no processo de retextualização. Sendo assim, a análise primou por observar a obliteração do significado ideacional através da: (1) omissão ou acréscimo de participantes pela análise da LSF; (2) influência das máximas de quantidade e modo no processo de tradução; (3) influência do caráter performativo do conteúdo proposicional.

\section{Resultados}

Os resultados obtidos, como esperado, tiveram pouca ou nenhuma variação de um semestre para o outro. Ou seja, o fator do tradutor possuir maior ou menor experiência com o idioma não apresentou desvio ponderável. O Quadro 2 (abaixo) apresenta as escolhas de tradução realizadas.

Quadro 2: Traduções realizadas pelos alunos (em número de ocorrências)

\begin{tabular}{|c|c|c|c|c|c|c|c|c|c|c|}
\hline \multirow[t]{2}{*}{ FLY BACK } & VOLTAR & $\begin{array}{l}\text { VOAR DE } \\
\text { VOLTA }\end{array}$ & RETORNAR & $\begin{array}{c}\text { VOLTAR DE } \\
\text { AVIÃO }\end{array}$ & $\begin{array}{l}\text { VOLTAR DE } \\
\text { VIAGEM }\end{array}$ & $\begin{array}{c}\text { VOO DE } \\
\text { RETORNO } \\
\text { (subst) }\end{array}$ & $\begin{array}{c}\text { não } \\
\text { respondeu }\end{array}$ & & & \\
\hline & 22 & 9 & 4 & 2 & 1 & 1 & 3 & & & \\
\hline \multirow[t]{2}{*}{ RIDE OUT } & $\begin{array}{l}\text { ANDAR DE } \\
\text { BICICLETA }\end{array}$ & ANDAR & PEDALAR & PASSEAR & SAIR & \begin{tabular}{|c|} 
SAIR \\
PEDALAND \\
0
\end{tabular} & $\begin{array}{c}\text { ANDAR DE } \\
\text { MOTO }\end{array}$ & $\begin{array}{c}\text { PASSEAR DE } \\
\text { BICICLETA }\end{array}$ & \begin{tabular}{|c|} 
CORER \\
PARA FORA
\end{tabular} & ENFRENTAR \\
\hline & 12 & 7 & 6 & 6 & 5 & 2 & 1 & 1 & 1 & 1 \\
\hline \multirow[t]{2}{*}{ WALK INTO } & ENTRAR & ADENTRAR & $\begin{array}{c}\text { ENTRAR } \\
\text { PARA } \\
\text { DENTRO }\end{array}$ & CAMINHAR & CHEGAR & IR & & & & \\
\hline & 26 & 9 & 2 & 2 & 2 & 1 & & & & \\
\hline \multirow{2}{*}{$\begin{array}{l}\text { WRITE } \\
\text { DOWN }\end{array}$} & ANOTAR & ESCREVER & CONTROLAR & $\begin{array}{c}\text { TOMAR } \\
\text { NOTA }\end{array}$ & REGISTRAR & DESCREVER & $\begin{array}{l}\text { ESCREVER } \\
\text { EMBAIXO }\end{array}$ & $\begin{array}{c}\text { não } \\
\text { respondeu }\end{array}$ & & \\
\hline & 24 & 6 & 2 & 2 & 2 & 2 & 1 & 2 & & \\
\hline \multirow[t]{2}{*}{ HAND BACK } & DEVOLVER & $\begin{array}{l}\text { DAR DE } \\
\text { VOLTA }\end{array}$ & & & & & & & & \\
\hline & 39 & 3 & & & & & & & & \\
\hline
\end{tabular}

Fonte: autores 
A partir desses resultados, em contraste com as acepções padrões dos PVs, temos o Quadro 3, a seguir.

Quadro 3: Porcentagem das acepções padrões

\begin{tabular}{|c|l|l|l|}
\hline \multicolumn{2}{|c|}{ PVs } & $\begin{array}{c}\text { Desvio da acepção padrão } \\
\text { em (\%) }\end{array}$ & \multicolumn{1}{|c|}{ Acepções padrões } \\
\hline \multirow{2}{*}{ FLY BACK } & Acepção fly & $71,42 \%$ das traduçöes & fly= voar \\
\cline { 2 - 5 } & Acepção back & $9,52 \%$ das traduções & back= de volta \\
\hline \multirow{2}{*}{ RIDE OUT } & Acepção ride & $47,61 \%$ das traduçöes & ride= andar de bicicleta \\
\cline { 2 - 4 } & Acepção out & $80,95 \%$ das traduçōes & out= para fora \\
\hline \multirow{2}{*}{ WALK INTO } & Acepção walk & $95,23 \%$ das traduçöes & walk=andar a pé \\
\cline { 2 - 4 } & Acepção into & $4,76 \%$ das traduções & into= para dentro \\
\hline \multirow{2}{*}{ WRITE DOWN N } & Acepção write & $7,14 \%$ das traduções & write= escrever \\
\cline { 2 - 4 } & Acepção down & $30,95 \%$ das traduçōes & down= a fim de lembrar, não esquecer \\
\hline \multirow{2}{*}{ HAND BACK } & Acepção hand & $0 \%$ das traduções & hand= entregar com as mãos \\
\cline { 2 - 4 } & Acepção back & $100 \%$ das traduções & out= de volta \\
\hline
\end{tabular}

Fonte: autores

\section{Análise e discussão dos resultados}

Omissão ou acréscimo de participantes pela análise da LSF

O que se observa logo de início é que, exceto para hand back, para o qual quase todos os alunos fizeram a mesma opção, não houve consenso nas traduções.

Utilizando o conceito de Leech e Svartvik (2002) sobre os PVs, que retêm os significados individuais do verbo e partícula (que é o caso de todos os PVs escolhidos para tradução), esperávamos que os alunos localizassem ambos os significados e buscassem transcrevê-los em português. Por exemplo, em "sit down" temos sentar + movimento para baixo. Os autores argumentam que em algumas línguas (como no português) o movimento fica condensado no verbo ("sentar"), ou é subentendido contextualmente.

Nas traduções realizadas pelos alunos, ficou claro que alguns verbos no português não "condensam" satisfatoriamente os significados trazidos por alguns PVs. O índice de discordância e a variação de escolhas evidenciam alunos inseguros com o valor semântico exato das proposições em português. Por exemplo, para write down, nesse contexto, sete opções de tradução foram apresentadas e ainda dois alunos, ao não responder, disseram não terem conseguido fazer a tradução. Isso indica que não há um verbo em português que condense 
satisfatoriamente o sentido Ideacional completo do PV na situação comunicativa em questão.

Fontaine (2013), na perspectiva da metafunção Ideacional da LSF, considera a partícula como circunstância quando esta for parte de um sintagma preposicional e carregar dentro de si algum significado. Por exemplo, em Please put your mask on the shelf. Nesse caso, put é considerado o processo e on, a circunstância. Já no caso de $\underline{\text { Put }}$ your mask on ou $\underline{\text { Put on }}$ your mask, tais formas verbais, separadas ou não por outras palavras, expressam um significado verbal e, consequentemente, a partícula se torna uma extensão do processo. Como em nossa análise os verbos escolhidos são do tipo verbo + circunstância, os alunos tiveram a opção de omitir ou acrescentar a circunstância (Quadro 4), ou ressignificar o processo, como veremos mais adiante.

Por exemplo, no caso da proposição de ride out, se considerarmos a grande maioria das traduções (26), temos:

Quadro 4 - Participantes

\begin{tabular}{|c|c|c|c|}
\hline$(\mathrm{He})$ & rode & out & in Mount Laguna \\
\hline Ator & Processo material & Circunstância & Circunstância \\
\hline
\end{tabular}

Fonte: autores

Nesse contexto, apenas alguns alunos decidiram não omitir o significado correspondente ao out (para fora). Resta saber, por que apenas cerca de $20 \%$ dos alunos decidiram omitir este significado.

A resposta a esse questionamento está provavelmente ligada às escolhas lexicogramaticais mais comuns e naturais utilizadas pelo nativo do português. Ao explicar a tipologia da língua, Talmy (1991) sugere que informações lexicais, como as de movimento, são expressas ou omitidas em elementos satélites ao verbo. Porém, o autor não considerou casos como hand back, para o qual quase $100 \%$ dos alunos, nesse contexto, optaram por traduzir apenas o movimento e desconsiderar completamente o verbo.

Portanto, as traduções dos alunos provaram que, tanto o significado do verbo, quanto o da partícula podem ser omitidos na ressignificação do processo em português. Nesses casos, a maioria dos nossos alunos preferiu, na tradução: 
- omitir o significado Ideacional da partícula para fly back, write down e walk into;

- omitir o significado Ideacional do verbo para ride out e hand back.

Sendo assim, as traduções dos PVs em línguas da tipologia satelitte-framed tendem a considerar, primeiramente, a busca de um referencial na língua alvo de verbo que condense os significados do PV na descrição do mesmo processo, e, caso não o encontre, a pesquisa mostrou que as opções de tradução incluem:

Quadro 5: Omissão de participantes

\begin{tabular}{|c|c|c|c|}
\hline$(\mathrm{I})$ & flew & back & to LA \\
\hline Ator & Processo material & Circunstância & Circunstância \\
\hline$(\mathrm{Eu})$ & voltei & $\mathrm{x}-\mathrm{x}-\mathrm{x}$ & para LA \\
\hline Ator & Processo material & $\mathrm{x}-\mathrm{x}-\mathrm{x}$ & Circunstância \\
\hline
\end{tabular}

Fonte: autores

Quadro 6: Acréscimo de participantes

\begin{tabular}{|c|c|c|c|}
\hline I & wrote down & \multicolumn{2}{|c|}{ every single meal } \\
\hline Ator & Processo mat. & nota & de cada refeição \\
\hline Eu & tomei & Escopo & Meta \\
\hline Ator & Processo mat. & Fota & Mautores \\
\hline
\end{tabular}

Fonte: autores

A partir da constatação de que algumas traduções de PVs são especialmente subjetivas ao tipo de escolha léxico-gramatical realizada, certamente espera-se alteração no conteúdo informacional, ou significado Ideacional (cf. LSF), transmitido no enunciado. A seguir, apresentamos alguns motivos que concorrem para a omissão ou acréscimo de participantes nesses casos.

Influência das máximas de quantidade e modo no processo de tradução

No caso de hand back, por exemplo, parece não haver problema nenhum em suprimir o modo de devolução (expresso por hand) nesse contexto. Provavelmente outros contextos podem apresentar resultados diversos e demandar o acréscimo de participantes ou até outras escolhas no sistema (p.ex., entregar). Nesses casos, parece-nos que o contexto preenche as lacunas informacionais necessárias para 
que o usuário da língua compreenda que tal devolução (mesmo que fosse expressa por give back no lugar de hand back) é procedida deste modo (entrega em mãos). Em contrapartida, um nativo do inglês, que possui give back, deliver e hand back como possibilidades de escolhas potenciais no sistema da língua, aplica especificidade à proposição ao selecionar uma dessas formas em detrimento da outra, possibilidade vedada ao falante de português, a menos que optasse por usar outro verbo, ou decidisse "engrandecer" a proposição com itens lexicais para acomodar todas as informações condensadas nos PVs - justamente porque o português é uma língua do tipo satélite. Desta forma, a tradução "devolver (com as)/ (nas) mãos", apesar de respeitar o valor informacional do verbo+partícula, foi opção completamente descartada por nossos alunos por ferir a Pragmática Conversacional.

Outro exemplo, na tradução para o português de "Flew back to $L A$ this morning", nossos alunos optaram por:

(1): Voltou/retornou para LA essa manhã - 26 ocorrências

$$
\begin{array}{llllll}
1 & 2 & 3 & 4 & 5 & \text { palavras }
\end{array}
$$

(2): Voou de volta para LA essa manhã - 9 ocorrências

Voltou de volta para LA essa manhã - 2 ocorrências

Voltou de viagem para LA essa manhã - 1 ocorrência

O que se pondera é que, nesse contexto, apenas as traduções em (1) são coerentes e correntes em português para os alunos analisados. As traduções em (2) são possíveis e coerentes, mas incomuns. Ou seja, diante de uma situação como essa, o tradutor precisa optar por perder conteúdo informacional na tradução (omissão do meio de regresso da viagem - avião), ou empregar uma escolha gramatical pouco comum para o contexto em questão.

Caso tentasse insistir em (2), o tradutor construiria um enunciado estranho ao leitor/ouvinte nativo do ponto de vista da Pragmática Conversacional - isso porque transgrediria as máximas da quantidade e de modo de Grice: "não dê mais informações que o necessário" e "seja breve (evite prolixidade desnecessária)". Em (2), o usuário da língua utiliza duas palavras a mais para realizar a mesma performance realizada com 5 palavras em (1).

Além disso, outro fato deve ser apontado quando a tradução é analisada na perspectiva da acepção padrão. Em termos de ocorrências (desconsiderando a conjugação no progressivo), realizamos uma pesquisa refinada no site Google e 
obtivemos (em 15 de junho de 2015), em inglês, para flew back home, aproximadamente 223.000 resultados.

Em português, consultamos as seguintes traduções e obtivemos:

- voou de volta para casa - Aproximadamente 5.570 resultados;

- voei de volta para casa - Aproximadamente 3.960 resultados;

- voaram de volta para casa - Aproximadamente 3.230 resultados;

- voamos de volta para casa - Aproximadamente 625 resultados.

Juntas, aproximadamente, as 13.000 ocorrências de variações de "voar de volta para casa" no pretérito perfeito em português não chegam sequer próximas das 223.000 ocorrências do correspondente em inglês, ou seja, tais escolhas léxicogramaticais não são tão comuns no português quanto no inglês, comprovadas pelo número de ocorrências ${ }^{3}$. Em contrapartida, são comuns as formas "retornou para casa" (65.800 ocorrências) e a massivamente superior "voltou para casa" (413.000). Esta última, portanto, deve ser tomada como acepção padrão no português brasileiro na atual conjuntura.

Sendo "voltar para (pra) a casa" a escolha preferencial em português, nota-se que ela omite um elemento exofórico que pode ser apenas recuperado no contexto situacional para uma completa interpretação do enunciado. O problema é que, nesse caso, a pessoa que está em outro país, por exemplo, pode voltar de trem, navio, avião, etc., e tal informação não aparece na tradução considerada padrão. Portanto, resta ao tradutor:

1) Forçar uma forma não comum/padrão e ser absolutamente fiel ao texto original em inglês - Ex.: "voar de volta para casa";

2) Escolher uma forma comum/padrão na língua alvo - Ex.: "voltar para (pra) a casa";

3) Optar pela reescrita e acrescentar ou retirar elementos ao texto original em inglês - "voltar para casa de avião".

Empregando (1), o tradutor causará estranheza ao leitor e, consequentemente, dificultará a leitura de um trecho que, em inglês, é natural para um nativo.

\footnotetext{
${ }^{3}$ Há de se relativizar o número de ocorrências em detrimento do banco de dados de ambos os idiomas.
} 
Ao empregar (2), o tradutor causará perda de conteúdo informacional (metafunção Ideacional), por omitir o elemento exofórico "avião", que está implícito em "voar".

$\mathrm{Na}$ tradução (3), optando pela reescrita, o tradutor acrescenta um elemento novo ao texto original (de avião) - uma circunstância que preenche a lacuna informacional deixada na substituição de "voar" por "voltar" no processo material, mas que pode porventura ferir o Princípio da Cooperação.

O que depreendemos desse raciocínio é que, caso o tradutor tente buscar uma tradução genuína dos PVs no nível gramatical, correrá grande risco de omitir conteúdo informacional quando este se referir a elementos exteriores ao texto. $\mathrm{O}$ ouvinte poderá preencher adequadamente ou não as lacunas necessárias para a construção de um significado completo do enunciado. Afinal, os alunos optaram por privilegiar a perda de conteúdo informacional (cf. item 2 supracitado), mas respeitando, assim, o Princípio da Cooperação (cf. Grice, 1989) - amparado na Pragmática Conversacional. O Princípio da Cooperação pacifica sobre o objetivo geral de produzir textos de modo a facilitar a interpretação, quando os interactantes buscam ser cooperativos uns com os outros. A análise das traduções desses PVs por nossos alunos demonstrou que, especialmente em situações de discordância sintática na tipologia linguística, a clareza está no cerne da ação tradutória e a violação das máximas foi expressamente evitada.

\section{Influência do caráter performativo do conteúdo proposicional}

No contexto da tradução dos PVs, muitas vezes a clareza da ação tradutória, abordada no item anterior, está associada com a performance expressa pelo verbo. Desta forma, muitas vezes o que se pondera é o ato de fala bem sucedido. Por exemplo, tomando o contexto hipotético de uma abordagem policial numa rodovia, o oficial pode dar o seguinte comando ao condutor (em inglês):

Step out of the car please.

Partindo do pressuposto que não há correspondente exato no nível gramatical para essa tradução em português, o tradutor tende a se aproximar do valor semântico da proposição com vistas ao seu caráter performativo. Portanto, pode oferecer a tradução: "Saia do carro, por favor". Há diferença entre tais proposições (inglês e português)? Provavelmente não, caso as consideremos somente por seu 
valor performativo, e o condutor realize a ação esperada pelo ato de fala, ou seja, sair do carro. Provavelmente sim, caso consideremos os outros significados construídos pela linguagem.

Em nossa análise, ao considerar o valor performativo aplicado a proposições como Why I Wrote Down Every Single Meal I Ate for a Year, as traduções oferecidas pelos alunos (anotar, escrever, tomar nota, controlar, registar e descrever) realizam a mesma performance de ação exterior ao texto. Ou seja, em situações como essa, geralmente, as variações de tradução não são percebidas ou diferenciadas pelo ouvinte.

Portanto, é provável que o ouvinte nativo do inglês que receba a comanda write down every single meal you eat e o ouvinte nativo do português que receba o mesmo comando, porém com "anotar", "escrever", "tomar nota", "controlar", "registar" ou "descrever", realizem exatamente a mesma ação: peguem um papel e uma caneta ou lápis e escrevam o que comem. Portanto, via de regra nesses casos, a diversidade tradutória dos PVs não causa problemas na situação comunicativa.

O mesmo não condiz com PVs que desencadeiam performances diferentes. Considerando o enunciado Rode out in Mount Laguna over the weekend e traduzindo-o por "Andou no Monte Laguna..." (segunda escolha preferida pelos alunos), o ouvinte pode realizar a performance a pé, a cavalo, etc. Esse fato, ulteriormente, pode criar equívocos interpretativos e alteração do significado informacional para a realização da performance. Caso o meio de realização da performance tenha sido um carro (o que é provável), a escolha léxico-gramatical oferecida (andou) não condiz com a acepção padrão no português

\section{Conclusão}

Os $P V s$ do inglês que, tradicionalmente, costumam desafiar tradutores $\mathrm{e}$ aprendizes da língua inglesa, analisados sob a perspectiva da Linguística SistêmicoFuncional e da Pragmática evidenciam que, nas traduções para o português, pode haver interferência, tanto na realização da concepção performativa da linguagem, quanto na compreensão de seu significado Ideacional ou Informativo, segundo a LSF. A resposta a esse questionamento está provavelmente ligada às escolhas léxico-gramaticais mais comuns e naturais utilizadas pelo nativo do português. Considerando-se a tipologia da língua, como argumentada por Talmy (1991), 
observamos que as informações lexicais, como as de movimento, são expressas através de circunstâncias ou omitidas. Em casos como hand back e ride out, a grande maioria dos alunos, considerando o contexto em que aparecia o PV, optou por traduzir apenas o movimento e desconsiderar completamente o verbo. Já com fly back, write down e walk into o significado da partícula foi minimizado e omitido pela maioria.

Portanto, as traduções dos alunos provaram que tanto o significado do verbo quanto o da partícula podem ser omitidos na expressão do processo. Assim, é um desafio do tradutor estar atento a essa omissão de significados e a sua relevância para a manutenção dos significados originais e ressignificação coerente na língua alvo. Além do mais, o que se pode notar em nossas análises é que, no momento da tradução de PVs para o português, uma língua com tipologia distinta do português pode determinar perda da noção de registro (formalidade e informalidade).

O que ocorre, muitas vezes, é que a tradução desses tipos de verbos frasais pode se mostrar invariavelmente mais formal ou distante do original, como observado em nosso corpus.

\section{Referências}

CELCE-MURCIA, M; LARSEN-FREEMAN, D. The grammar book: an ESL / EFL teacher's course. Rowley, MA: Newbury House, 1983.

CHARTERIS-BLACK, J. Corpus approaches to critical metaphor analysis. New York: Palgrave-MacMillan, 2004.

CORNELL, A. Realistic goals inteaching and learning phrasal verbs. IRAL, n. 23, p. 269-280, 1985.

DAGUT, M.; LAUFER, B. Avoidance of phrasal verbs: A case for contrastive analysis. Studies in Second Language Acquisition, n. 7, p. 73-79, 1985.

DARWIN, C. M.; GRAY, L. S. Going after the phrasal verbs: an alternative approach to classification. TESOL Quarterly, n. 33, p. 65-83, 1999.

DIXSON, R. The grammar of English phrasal verbs. Australian Journal of Linguistics, n. 2, p. 1-42, 1982.

FAIRCLOUGH, N. Discourse and social change. Cambridge: Polity Press, 1992. 
FILLMORE, C. J.; ATKIND, B. T. Towards a Frame-Based Lexicon: the semantics of risk and its neighbours. In.: LEHRER, A.; KITTAY, E. V. (Eds.). Frames, films and contrasts: new essays in semantic and lexical organization. Hillsdale, NJ: Erlbaum, 1992, p.75-102.

FONTAINE, L. Analysing English grammar: a systemic functional introduction. New York: Cambridge University Press, 2013.

FOWLER, A. Language in the news. New York: Routledge, 1991.

GRICE, P. H. Logic and conversation. In: Cambridge, MA: Harvard University Press, 1989, p. 22-40.

Studies in the way of words.

HALLIDAY, M.A.K. An introduction to functional grammar. London: Edward Arnold, 1985, v. 2.

. Functional grammar. London: Edward Arnold, 1994.

HALLIDAY, M. A. K.; MATTHIESSEN, C. M. An introduction to functional grammar. 3.ed. London: Arnold, 2004.

HILTUNEN, R. Verbal Phrases and Phrasal Verbs in Early Modern English. In: BRINTON, L.J.; AKIMOTO, M. (Eds.) Collocational and idiomatic aspects of composite predicates in the history of English. Amsterdam; Philadelphia: John Benjamins, 1999, p. 133-166.

LEECH, G; SVARTVIK, J. A communicative grammar of English. Essex: Pearson Education, 2002.

NEVALAINEN, T. Early modern English lexis and semantics. In: LASS, R.; HOGG, R. (Eds.) The Cambridge history of the English language. Cambridge: Cambridge University Press, 1992, vol 3.

SANTOS, H. W. B; NOGUEIRA, R. C. O Ensino e a aprendizagem de phrasal verbs. Ao pé da letra, Recife, v. 6, n. 2, p. 156-166, 2004. Disponível em: <http://revista aopedaletra.net/volumes-aopedaletra/vol\%206.2/O_ensino_e_a_aprendizagem_de_ Phrasal_Verbs.pdf>. Acesso em: 02 jun. 2015.

SIDE, R. Phrasal verbs: sorting them out. In: English Language Teaching Journal, v. 44, n. 2, p. 144-152, 1990.

SOUZA FILHO, D. A Teoria dos atos de fala como concepção pragmática de linguagem. Revista Filosofia Unisinos, v. 7, n. 3, p. 217-230, 2006. Disponível em: <http://revistas.unisinos.br/index.php/filosofia/article/view/6101/3277>. Acesso em: 02 jun. 2015.

SWAN, M. Practical English Usage. Oxford: Oxford University Press, 1995. 
$\mathbb{B}_{\text {disse }} \mathcal{A}$

TALMY. L. Paths to realization: a typology of event conflation. In: Proceedings of the Seventeenth Meeting of the Berkeley Linguistics Society. Berkeley: Berkeley Linguistics Society, 1991, p. 480-519.

THIM, S. Phrasal verbs: the English verb-particle construction and its history. Berlin: Walter de Gruyter, 2012.

THOMPSON, G. Introducing functional grammar. New York: Routledge, 2014. 